\title{
Os polímeros como biomateriais
}

\section{1 - Introdução}

É do conhecimento geral o grande desenvolvimento da medicina nos últimos anos, quer no que respeita a prevenção de doenças quer, de um modo mais sensacionalista, do ponto de vista cirúrgico, pela própria propaganda de que é rodeado. Neste último caso têm especial relevo as transplantaçōes (recordemos recentemente, a primeira transplatação cardíaca em Portugal). $\mathrm{Na}$ realidade hoje em dia é possível transplantar qualquer órgão ou qualquer tipo de tecido (os suecos estudam já a cura de certas doenças neurologicas através de transplantaçסes de tecido cerebral), desde que se verifiquem certas condiçøes de compatibilidade fisiologica.

Se do ponto de vista técnico o processo é possível, do ponto de vista humano torna-se bastante mais complexo, pois por vezes é necessário um órgão vital que não pode ser retirado a uma pessoa para ser dado a outra. Por outro lado vários problemas psicológicos e religiosos levam poucas pessoas a declarar quererem ser doadores depois da morte. Este aspecto pode levantar problemas jurídicos aquando da utilização de orgãos sem a autorização prévia dos familiares do indivíduo que morreu. Há ainda a hipótese do doador ser um animal, mas, também aqui, problemas de ordem psicológica impedem que o processo se verifique frequentemente. Resta então procurar órgãos e materiais não biologicos - biomateriais - (naturais ou sintéticos) que desempenhem as funçðes daqueles que é necessário substituir. Embora dito pareça extremamente fácil, uma vez que nos habituámos a ver o homem substituir por materiais sintéticos um grande número de produtos naturais (fibras, cabedal, madeira, etc.) torna-se muito complicado substituir a natureza num sistema tão complexo como o corpo humano.

Dissemos que quando há um doador se têm que verificar certas condiçð̄es de compatibilidade fisiologica para evitar a rejeição do tecido transplantado. $O$ facto de estas condiçðes não se porem entre o receptor e um tecido sintético poderia levar a pensar que os problemas de rejeição biológica por reacçðes imunológicas seriam diminuídos. No entanto verificou-se que os materiais não eram inertes mas "reagiam" com o meio biologico. É assim necessário considerar o problema global e complexo da interacção entre o receptor e o material se se pretende que este seja bem recebido.

\section{2 - Biomateriais}

Por incrivel que pareça a historia dos biomateriais perde-se no tempo pois já em papiros "datados" de $\mathbf{4 0 0 0}$ a.C. se descrecem suturas e outros dispositivos para fechar feridas. De 2000 a.C. data, talvez, o primeiro registo do uso de metais para reparar ossos partidos. Já no passado mais recente data de 1550 a descrição do uso de suturas de ouro assim como de um palato de ouro. Em 1800 era já vulgar o uso de placas e parafusos metálicos em ortopedia.

No século XX com o desenvolvimento da ciência dos materiais, e da indústria dos polímeros em particular, surge uma imensidade de novos materiais que começam a ser utilizados, acompanhando o desenvolvimento das técnicas cirúrgicas.

No entanto, apesar da necessidade premente de Biomateriais, marcos importantes da sua história têm surgido sempre com uma consequência do desenvolvimento de polimeros industriais. Assim, por exemplo, embora com várias contribuiçø̋es anteriores o primeiro rim artificial (aparelho de hemodiálise) utilizável, apresentado pelo Dr. Kolf em 1944 só foi possivel depois do desenvolvimento de tubos de celofane para enchidos, e a hemodiálise só se implementou como rotina depois do aparecimento da polisiloxana e do politetrafluor-etileno, que permitiram fazer ligaçøes $A / V$.

Vemos, assim, que a evolução dos Biomateriais tem dependido em grande parte da evolução da ciência dos materiais. Hoje em dia são usados como biomateriais metais, cerâmicos e polímeros. No entanto, dada a possibilidade de serem sintetizados com características estabelecidas à priori, os polímeros são, sem dúvida, os que têm uma utilização mais variada.

\section{3 - Polímeros com biomateriais}

O uso de polímeros como biomateriais vai desde aplicaçð̃es temporárias como suturas, balóes aórticos, a aplicaçø̃es de carácter mais permanente como enxertos vasculares, em cirurgia plástica e reconstrutiva, válvulas cardíacas, articulaçð̃es, etc. São inclusivamente usados em "aparelhos"'mais complexos que se pretende que desempenhem certas funçø̃es fisiológicas - os órgãos artificiais - (coração, pulmão, rim, pâncreas).

No entanto, qualquer que seja a sua aplicação, há que atender a certos requisitos dos quais se destacam:

- Compatibilidade

- Não toxicidade

- Estabilidade no ambiente biológico

- Propriedades físicas apropriadas

- Possibilidade de ser esterilizado

- Possibilidade de ser fabricado

Dos vários aspectos mencionados os dois últimos pontos são os mais facilmente ultrapassáveis pois não estão directamente relacionados com o facto do polímero ir ser implantado no complexo ambiente biológico.

Por outro lado, é também difícil separar de modo absoluto os 3 primeiros pontos. Na verdade, um polimero que seja compatível não será em princípio "atacado" pelo meio biologico alterando-o. Por outro lado a

- Prof. Auxiliar do IST 
toxicidade de um polímero é muitas vezes resultado da sua degradação no ambiente biológico que leva à libertação de produtos tóxicos. Estes produtos mesmo quando não tóxicos, podem dar origem a reacçð̄es de rejeição levando a que o polimero seja considerado como não compatível.

A complexidade do fenómeno é agravado pelo facto de até recentemente poucos polímeros terem sido desenvolvidos para utilizaçőes médicas. $\mathrm{Na}$ verdade, tal como foi dito, dado o grande desenvolvimento da indústria dos polímeros e a grande variedade de polímeros industriais existentes, foi sempre procurado entre estes um que satisfizesse as necessidades médicas. No entanto os polimeros industrais são sempre fabricados com uma série de aditivos que podem mascarar todo o problema de compatibilidade. Uma vez que os aditivos são mais facilmente extractáveis poderão provocar ou mascarar uma reacção de rejeição. Vejamos alguns exemplos.

Quando Leib (1959) implantou em coelhos, para avaliar da sua compatibilidade, amostras de polimetilmetacrilato os resultados foram diferentes consoante a marca comercial: assim, enquanto amostras de Lucite $^{R}$ produziram muito pouca reacção nos tecidos adjacentes, amostras de Plexigas ${ }^{R}$ produziram inflamaçōes agudas e crónicas. Uma vez que todas as amostras eram basicamente o mesmo polímero a diferença na compatibilidade era devida aos aditivos usados.

Por volta de 1960 desenvolveu-se a técnica ao "entubar" doentes. Eram usados tubos de PVC comercial. O PVC é um plástico que é normalmente fabricado com vários aditivos o que poderia levar a reacçðes diferentes dos tecidos adjacentes. Na verdade verificou-se que alguns destes tubos provocavam uma rejeição simultaneamente com efeitos tóxicos. Investigado o assunto provou-se que os tubos em que se verificavam reacçøes adversas tinham sido todos estabilizados com compostos organometálicos de estanho, o mesmo não acontecendo com os restantes.

A própria forma do implante condiciona a reacção dos tecidos. Assim, está provado que a existência de arestas vivas a aumenta.

Dada a grande aplicabilidade dos polímeros como biomateriais e a grande complexidade do processo de interacção dos materiais com o ambiente biologico não é possível definir em absoluto se determinado polimero é ou não compativel. A compatibilidade dependerá do fim para que for usado. Assim, enquanto que o politetrafluoretileno é dos materiais que provocam menos reacção quando implantado intramuscularmente é um material extremamente trombogénico, ou seja, provoca uma reacção violenta por parte do sangue quando em contacto com este tecido.

Vejamos então a aplicabilidade dos polímeros em várias situaçס̃es.

\section{1 - Polímeros em ortopedia}

A maior parte dos materiais sintéticos usados em ortopedia são, ainda hoje, os metais. Há no entanto alguns casos em que a utilização de polímeros está já consagrada. É por exemplo o caso da componente acetabular numa prótese total de anca em que é usado polietileno UHMW (peso molecular de ordem $2 \times 10^{6} \mathrm{e}$ densidade 0.93 ). A componente femural da prótese é normalmente metálica, sendo introduzida no compartimento medular do fémur. As componentes da prótese são fixadas usando um cimento polimérico: polimetilmetacrilato, polimerizável in situ.
Embora de utilização corrente este cimento traz vários problemas: a libertação de vapores do monómero pode interferir com a função sistémica, diminuindo a tensão arterial; o facto da polimerização ser altamente exotérmica pode causar um aumento da temperatura local que pode levar a necrose celular; por outro lado a extensa preparação da cavidade medular que é necessário fazer pode bloquear as.sinusóides ósseas provocando necrose dos tecidos.

Estes factos levam a que estejam em estudo outros tipos de cimentos e outros tipos de próteses, nomeadamente metálicas cobertas de feltros poliméricos, que possam ser usadas sem cimento.

Polímeros são também usados em articulaçōes mais "pequenas", como por exemplo, as articulaçōes dos dedos que são, na grande maioria, de Polietileno UHMW ou polipropileno.

Polimeros - (fibra de carbono ou compósitos de fibra de carbono) começam também a substituir as placas metálicas usadas para reparar fracturas em ossos longos. A sua vantagem reside no facto de que o módulo de elasticidade dos materiais utilizados, possibilitando o movimento, estimula a formação de calo, logo a recuperação do osso.

\section{2 - Polímeros em odontologia}

Neste caso os polímeros são principalmente usados em dentaduras e em dentes artificiais que cobrem "pivots" metálicos. Na escola do polímero há que ter em atenção o ambiente agreste que a boca representa: alteração constante de $\mathrm{pH}$, de composição química, de temperatura, fácil desenvolvimento de bactérias, além das tensōes de compressão e deslizamento a que ficarão sujeitos durante a mastigação.

Entre os vários polimeros utilizados mencionam-se compósitos de politetrafluoretileno e polimetilmetacrilato.

\section{3 - Polímeros para substituir tecidos maleáveis}

É aqui sem dúvida que os polímeros tem um maior campo de aplicabilidade.

Pode-se dizer que para substituir em tecido maleável, um material sintético deverá duplicar razoavelmente a textura do tecido que se propōe substituir, por tempo indefinido, causando o mínimo incómodo ao doente.

Vemos assim que um material que se altere uma vez implantado, quer perdendo constituintes, quer por ataque enzimático, quer ainda por absorção de fluidos biologicos não pode ser utilizado como substituinte de tecido maleável.

Pelo mesmo princípio a reacção nos tecidos adjacentes ao implante deve ser mínima. Assim, a formação de tecido fibroso pode provocar um endurecimento, de tal modo que se perde a maleabilidade inicial.

Podemos considerar várias aplicaçð̃es especificas.

\subsection{1 - Suturas}

As suturas sintéticas têm vindo a substituir as naturais (catgut, algodão e seda) uma vez que causam menos infecção que estas.

As suturas são os "fios" com que normalmente os cirurgiðes "cosem". Estes fios podem ser monofilamentos ou polifilamentos.

Podem ainda distinguir-se suturas absorvíveis e não absorvíveis. As suturas absorvíveis (nylon, ácido poliglicólico) causam reacção nos tecidos, a qual diminui à medida que o material vai sendo degradado.

Como materiais para suturas não absorviveis são usados poliester, poliacrilonitrilo, e polipropileno. 


\subsection{2 - Implantes percutâneos}

Este tipo de implantes têm vários problemas e não é fácil conseguir que obedeçam à condição focada anteriormente... "por tempo ilimitado". Na verdade, o implante atravessa a pele e, a região de contacto pele-ar-implante é extremamente crítica, pois qualquer abertura que permita a passagem de bactérias irá originar uma infecção. Por outro lado a pele é um tecido dinâmico pelo que é difícil manter um "selo" entre a pele e o implante.

Vários modelos têm sido propostos consoante, entre outros aspectos, a finalidade do implante. No entanto um dos polímeros mais utilizados independentemente do "design" é o poliuretano.

\subsection{3 - Pele artificial}

Os problemas neste caso são semelhantes aos anteriores embora em maior escala. É necessário encontrar um material que adira a uma extensa área de modo a evitar a perda de fluidos biológicos.

A figura seguinte esquematiza alguns dos problemas que podem surgir.

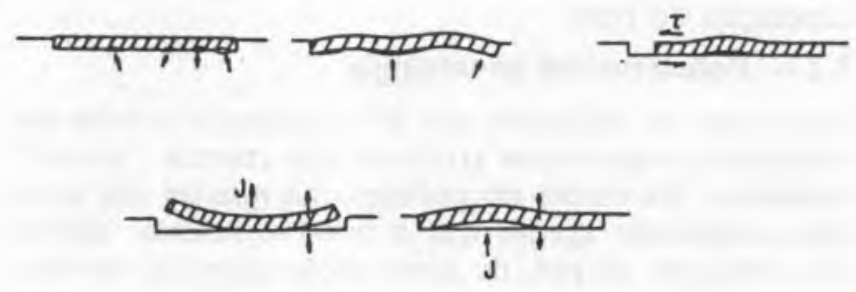

Assim, se a aderência não for suficiente surgem bolsas de ar, donde a infecção; o mesmo acontece se o material usado não for suficientemente flexível para acompanhar o tecido vivo. Uma tensão de deslizamento pode ocasionar um "engelhar" do material e assim a formação de bolsas de ar. Um fluxo de humidade demasiadamente grande através do implante pode provocar uma deshidratação, ao mesmo tempo que leva a que o material seque e se separe da ferida; por outro lado um fluxo demasiadamente pequeno pode levar a uma acumulação de fluído entre a ferida e o material.

Vários polímeros têm sído usados para isolar queimaduras, entre os quais copolimeros de cloreto e acetato de vinilo, esponjas de álcool polivinílico e tecidos de nylon e silicone. No entanto, a pele artificial mais promissora é a desenvolvida por Yannas e Bruke a partir de colagénio e polisacarídeos.

\subsection{4 - Cirurgia plástica e reconstrutiva}

Vários polimeros têm sido usados consoante o fim que se pretende. Assim, no caso de reconstrução de mandibulas apenas silicone e Teflon ${ }^{\mathrm{R}}$ em blocos têm sido usados. Ambos são facilmente fabricados na forma desejada.

A borracha de silicone tem ainda sido utilizada para corrigir queixos, narizes e cavidades orbitais. Por vezes a prótese é envolvida por um tecido poroso (feltro, malha, etc. em Dacron ${ }^{\mathbb{R}}$, por exemplo) para facilitar a sua fixação através de crescimento do tecido natural nos interstícios.

$O$ Teflon $^{R}$ tem aplicaçð̃es semelhantes às da borracha de silicone podendo inclusivamente ser tecido quando há a necessidade de um tecido poroso.

De entre outros polímeros usados neste tipo de cirurgia é de destacar o tecido de politeraftalato de etileno (Da-
$\operatorname{cron}^{\mathrm{R}}$ ) impregnado em polieteruretano e um material compósito de Teflon ${ }^{R}$ e fibras de carbono (Proplast ${ }^{R}$ ). $O$ polímero mais utilizado como material de enchimento de cavidades é a borracha de silicone. Surge como uma consequência de relativa compatibilidade e estabilidade do polímero alheado à possibilidade de, através de um controlo de peso molecular, mimar a maleabilidade dos tecidos.

Assim, por exemplo, depois de uma mastectomia total quando se pretende substituir a mama utiliza-se um gel de silicone envolvido por um saco de filme de silicone que por sua vez está envolvido em gaze de poliester para permitir a sua fixação através do crescimento dos tecidos adjacentes.

Convém referir que este crescimento dos tecidos adjacentes é no fundo uma reacção ao implante, que neste caso, no entanto, é desejável. Nos primeiros tempos da cirurgia plástica da mama eram utilizadas esponjas de álcool polivinílico; no entanto, com o tempo, dava-se a calcificação dos tecidos que se tinham formado nos interstícios da esponja perdendo o implante a flexibilidade desejada.

$O$ pénis, testículos e vaginas artificiais englobam-se na mesma classificação de enchimento de cavidades, sendo utilizados processos equivalentes.

\subsection{5 - Implantes no ouvido e nos olhos}

No caso dos ouvidos os implantes poliméricos são usados para substituir ossículos que por alguma razão impedem a audição. Entre os polímeros usados salienta-se o polimetilmetacrilato (PMMA), polietileno, Teflon ${ }^{R}$, Proplast $^{R}$, polietileno poroso (Plastipore ${ }^{R}$ ) e borracha de silicone.

Nos olhos os implantes pretendem restituir a funcionalidade da córnea e da lente intraocular. Têm assim de ser polímeros transparentes, sendo o PMMA o mais utilizado. No caso de implantes na córnea surgem grandes dificuldades de fixação como bem se compreende.
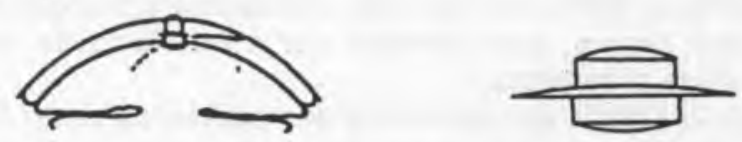

O problema não é tão grave no caso das lentes intraoculares, que começam a estar bastante divulgadas no caso de cirurgia às cataratas. A "lente" de PMMA é fixada através de "molas" de polietileno

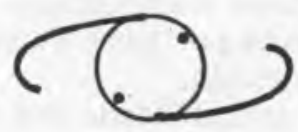

\subsection{6 - Polimeros em contacto com o sangue}

Quando se pretende que uma prótese esteja em contacto com o sangue todo o problema de compatibilidade se agudiza, pois enquanto que com implantes noutros tecidos se pode tolerar uma certa incompatibilidade e reacçס̄es inflamatórias, uma vez que são localizadas, no caso de contacto com o sangue a primeira prova de incompatibilidade pode ser o início de coagulação, que pode comprometer não só o funcionamento do implante; pode haver paragem do fluxo de sangue ou o trombo sanguíneo ser arrastado para algum orgão vital. Para melhor compreender o problema é necessário dizer alguma coisa acerca do sangue. $O$ sangue é um sis- 
tema heterogéneo constituído por plasma e elementos celulares em suspensão. O plasma é a parte líquida do sangue, constitui aproximadamente $5 \%$ do peso do corpo humano e contém um grande número de iðes e proteinas. Os elementos celulares são os globulos vermelhos, com a forma de lente biconvexa, os globulos brancos e as plaquetas, que são os elementos celulares de menores dimensőes. A viscosidade do sangue é aproximadamente cinco vezes a da água, mas depende da concentração em elementos celulares.

Uma superficie para ser compativel com um sistema tão complexo como o sangue tem de obedecer a vários requisitos, como não causar

- trombose

- destruição dos elementos celulares

- alteração das proteinas do plasma tais como albumina, globulinas e fibrinogéneo

- destruição de enzimas

- desequilibrio electrolítico,

além de não provocar reacçðes alérgicas, não ser tóxico ou carcinogéneo, o que aliás se tem que verificar em contacto com qualquer outro tecido.

O sangue circula nos vasos sanguíneos de maiores dimensðes em regime laminar. Para uma velocidade critica o regime torna-se turbulento. Quanto maior o número de Reynolds maior a probabilidade de surgir este regime. A possibilidade de destruição de elementos celulares do sangue por uma superficie artificial depende do regime de escoamento. Uma superfície pode ser totalmente destruidora num regime e absolutamente inofensiva noutro. Este facto levou a que se desenvolvesse um grande esforço no "design" de peças em contacto com o sangue. É o caso das válvulas cardíacas em que o sucesso obtido se baseia em grande parte num "design" cuidadoso.

Muito resumidamente, quando o sangue entra em contacto com uma superfície artificial dá-se a coagulação do sangue, em que, por um processo em cascata o fibrinogéneo se transforma em fibrina ao mesmo tempo que há adesão de plaquetas à superfície com a consequente agregação daquelas umas às outras. Dependendo do regime assim se forma um trombus branco, principalmente constituído por plaquetas e fibrina (regiōes de grandes gradientes de velocidade) ou um trombus vermelho, principalmente constituido por globulos vermelhos e fibrina (regióes de pequenos gradientes de velocidade). A importância relativa da coagulação do plasma e da adesão de plaquetas, além de depender do regime de escoamento do sangue, depende da superficie. Sabe-se hoje em dia que é mais difícil evitar a adesão de plaquetas que a coagulação do plasma.

Pô-se então a questão: quais as características que uma superfície deve ter para ser compatível com o sangue? Depois de tantos anos esta pergunta continua sem resposta devido à complexidade do sangue (o qual difere inclusivamente de pessoa para pessoa) e ao facto de não ser ainda completamente conhecida a sequência de acontecimentos depois do contacto do sangue com um material sintético.

Enquanto a verdadeira questão fica por resolver vários polímeros têm sido utilizados consoante a estratégia para minimizar os "danos".

Assim, por exemplo para vasos sanguíneos de grandes dimensðes polímeros tecidos de nylon, poliacrilonitrilo, politereftalato de etileno dada a facilidade de manuseamento. Neste caso a estratégia é provocar a formação de fibrina e tecido fibroso que mais tarde se transforma em neointima.
Esta estratégia não pode no entanto ser seguida no caso de vasos sanguíneos de pequenas dimensóes uma vez que o coágulo de fibrina obstruiria completamente o mesmo. Há assim que utilizar outras estratégias evitando a formação de trombus.

Uma outra estratégia tem sido alterar a superfície dos polímeros como que "enxertando" moléculas anticoagulantes na esperança que assim se evitaria a coagulação. Dentro da mesma estratégia de tornar o implante anticoagulante está a ser desenvolvida em França um polímero que partindo do anticoagulante natural heparina possa ser fabricado na forma de tubo.

A observação de que o tempo de coagulação do sangue aumenta quando um recipiente de vidro é revestido com parafina, levou a pensar-se que os polímeros a utilizar em contacto com o sangue deveriam ser hidrofóbicos. Hoje em dia esta teoria está posta de parte pois a superficie de um polímero ao entrar em contacto com o sangue é imediatamente coberta com proteínas do sangue alterando a hidrofilicidade. A sua compatibilidade é assim em última análise função deste primeiro acontecimento - quais as proteínas adsorvidas preferencialmente, desnaturação ou não destas proteinas, equilibrio de adsorção desorpção que se estabelece, etc. De entre os polímeros "neutros" utilizáveis hoje em dia são de salientar polisiloxano, Teflon ${ }^{R}$ e polieteruretano.

As borrachas de silicone no entanto não podem ser utilizadas em implantes de longa duração pois adsorvem os lípidos do sangue alterando as características mecânicas do implante.

O Teflon ${ }^{R}$, embora como vimos, seja compatível com tecidos biológicos é pouco compativel com o sangue, pelo que embora, muito utilizado, é-o apenas em regiôes em que o fluxo sanguíneo é elevado como é o caso das válvulas cardiacas. As suas propriedades mecânicas não são alteradas.

Os polieteruretanos (Biomer ${ }^{R}$ e Avcothane ${ }^{R}$ ) são sem dúvida os polímeros mais utilizados em enxertos vasculares de pequeno diâmetro dada a sua compatibilidade e propriedades mecânicas.

Outros polímeros utilizados em válvulas cardíacas são o polipropileno, o polioximetileno, e o policlorotrifluoretileno.

\subsection{7 - Polímeros em órgãos artificiais}

A aplicação de polimeros em órgãos artificiais é um caso particular do que foi dito anteriormente.

Assim, na máquina coração-pulmão usada, durante cirurgia cardíaca, há a consolidar os tubos por onde o sangue circula extracorporalmente, normalmente de borracha de silicone (Silastic ${ }^{\mathrm{R}}$ ), e a membrana do oxigenador do sangue onde se dão as trocas gasosas: o sangue recebe $\mathrm{O}_{2}$ e perde $\mathrm{CO}_{2}$. Esta membrana é normalmente de borracha de silicone ou Teflon ${ }^{R}$.

Por vezes utilizam-se bombas de balão normalmente feitas de poliuretano (Avcothane ${ }^{\mathrm{R}}$ ), para ajudar a circulação cardíaca.

No caso dos coraçðes artificiais recentemente implantados nos Estados Unidos, nomeadamente no famoso Jarvik 7 foi utilizado um polieteruretano em vários elementos.

No caso do rim artificial ou aparelho de hemodiálise há do mesmo modo a considerar os tubos de circulação extracorporal e a membrana de diálise que deverá permitir a passagem de ureia, sódio, cloretos, bicarbonatos, glucose, e ácido úrico.

À membrana é pedido que seja compativel com o san- 

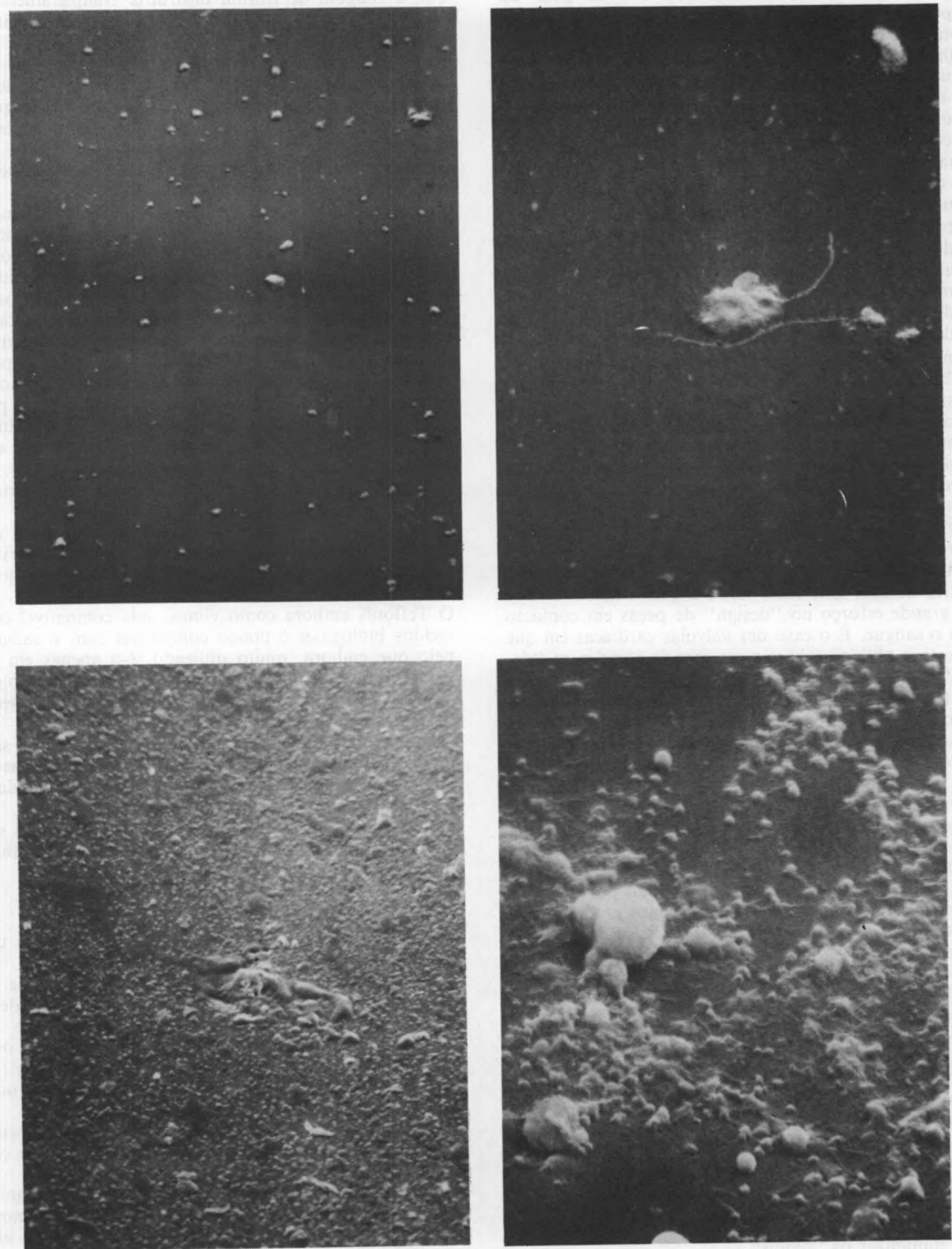

Duas superficies de politeruretano de diferentes composiç̃es, obtidas por microscopia electrónica de varrimento (SEM), depois de contacto com o sangue. A superfície b é bastante mais trombogénica 
gue para evitar a necessidade de administrar antigoagulantes, que seja suficientemente resistente quando molhada para permitir a ultrafiltração, que permita a passagem dos elementos nocivos de baixo peso molecular evitando a passagem de proteínas do sangue.

A grande maioria das membranas usadas são feitas de celofane, derivado da celulose, que é um polímero natural.

Outros polímeros têm também sido usados em membranas de diálise como por exemplo copolímeros de polietilenoglicol e politereftalato de etileno.

Um outro aspecto na utilização de aparelhos de diálise é a necessidade de um implante percutâneo com os problemas já focados.

Apesar de serem já largamente utilizados como biomateriais, várias questões estão ainda por solucionar e bastante mais investigação é necessária no domínio dos polímeros.

É fundamental continuar o esforço de desenvolver polimeros especificamente para aplicaçð̄es biomédicas abandonando a atitude cómoda de utilizar o que está disponível industrialmente.

O problema é muito complexo e a razão da grande per- centagem de fracassos durante os primeiros tempos da utilização de polímeros foi devida ao facto dos polímeros utilizados serem polímeros industriais, fabricados sem cuidados especiais para o fim a que estavam a ser utilizados.

Para minimizar os problemas que podem surgir e comprometer os processos envolvidos torna-se necessário uma muito estreita colaboração entre químicos, especialistas em ciências dos materiais, biologistas e médicos, para que materiais especialmente concebidos e rigorosamente puros sejam sintetizados e testados da maneira mais apropriada.

\section{Bibliografia}

R. Leininger - Polymers as surgical implants CRC, Critical Reviews in Bioengineering, 333, Outubro 1972.

D. J. Lyman - Polymers in Medicine Angew Chem. Int. Ed. 13108 (1974).

E. Chielline, P. Giusti. ed., Polymers in medicine - Biomedical and pharmacological application, Plenum Press (1983).

Polymers in Medicine - 2nd International Conference Abstracts Capri 1985.

J. B. Park, Biomaterial Science and Engineering, Plenum Press, 1984. 


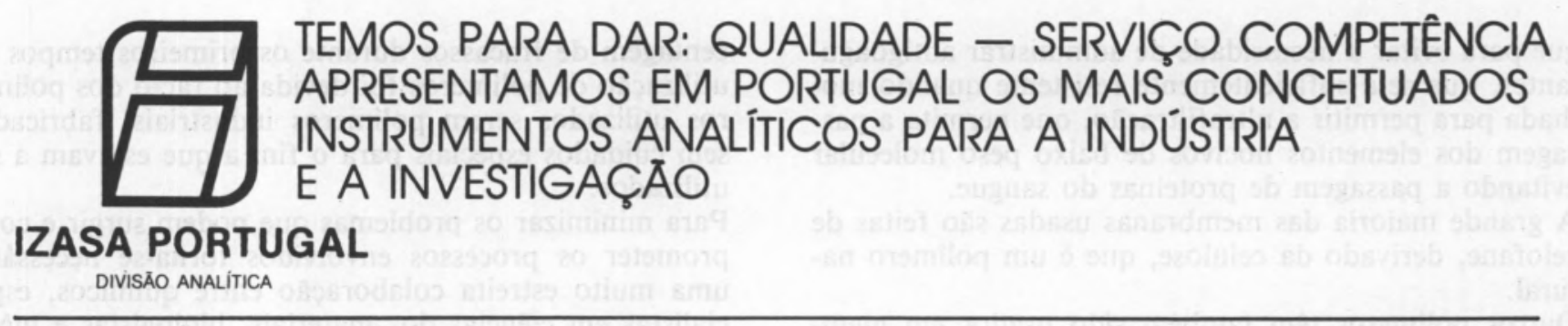

\section{LKB \\ BROMMA}

Electroforese vertical e horizontal, Focagem isoeléctrica, Cromatografia liquida H. P. L. C. - CALORIMETRIA

LKE WALLAC

Contadores Gama, Contadores Beta, Luminómetros

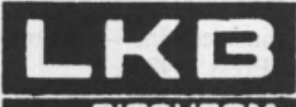

BIOCHAOM

Analisadores de Aminoácidos e Péptidos, Espectrofotómetros UV/visivel

\section{[mimicromerities ${ }^{\circ}$}

Picnómetros, Porosimetros, Analisadores de áreas superficiais, Contadores de particulas

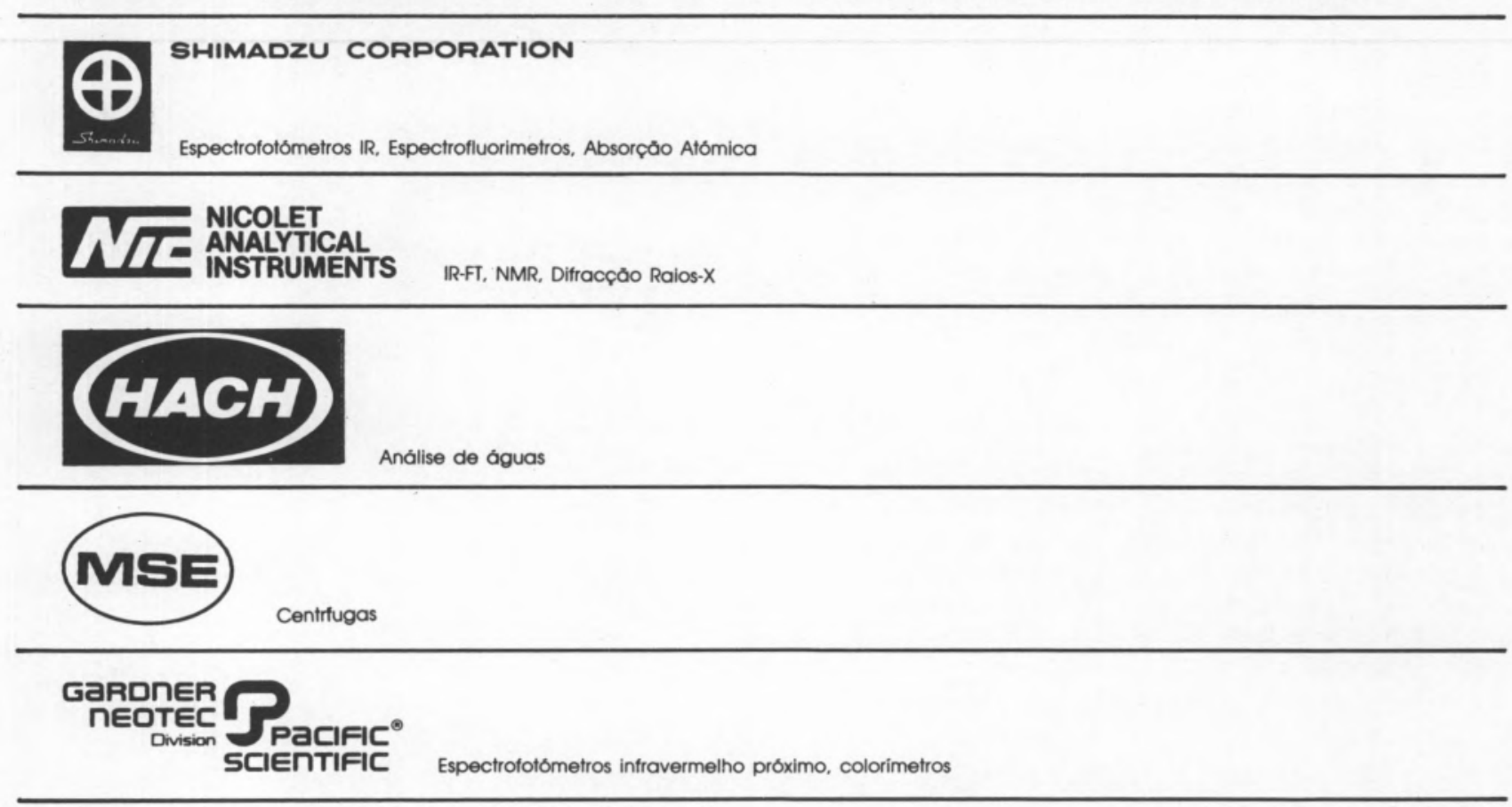

\section{龱tecator}

Aparelhos de Kjeldahl, Soxhlet, Fibertecs $\theta$ análises por FIA

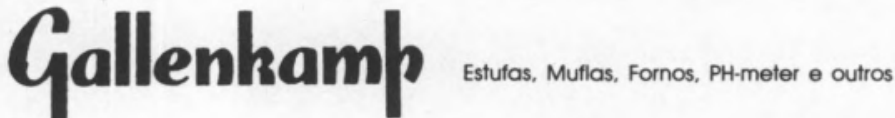

\section{AGUARDAMOS A VOSSA SOLICITAÇÃO.}

ESTAMOS EM LISBOA:

Av. Ventura Terra, 15, retaguarda, 1. ${ }^{\circ}$ - Telefs. $7587728-7580740$-Telex $42536-1600$ usBOA

E NO PORTO: Largo Soares dos Rels, 50 - Telet. 306671 - Telex 26799 - 4400 VILA NOVA DE GAIA 